\title{
Size-induced amorphous structure in tungsten oxide
}

\section{nanoparticles}

Mikkel Juelsholt, ${ }^{1}$ Andy S. Anker, ${ }^{1}$ Troels Lindahl Christiansen, ${ }^{1}$ Mads Ry Jørgensen, ${ }^{2,3}$ Innokenty Kantor, ${ }^{2,4}$ Daniel Risskov Sørensen, ${ }^{2,3}$ and Kirsten M. Ø Jensen ${ }^{1 *}$

1: Department of Chemistry and Nano-Science Center, University of Copenhagen, 2100 Copenhagen $\varnothing$, Denmark

2: Department of Chemistry \& iNANO, Aarhus University, 8000 Aarhus C, Denmark 3: MAX IV Laboratory, Lund University, 22484 Lund

4: Department of Physics, The Technical University of Denmark, 2880 Lyngby, Denmark

KEYWORDS: Tungsten oxide, nanostructure, X-ray total scattering, Pair Distribution Function Analysis

The properties of functional materials are intrinsically linked to their atomic structure. When going to the nanoscale, size-induced structural changes in atomic structure often occur, however these are rarely well-understood. Here, we systematically investigate the atomic structure of tungsten oxide nanoparticles as a function of the nanoparticle size and observe drastic changes when the particles are smaller than $5 \mathrm{~nm}$, where the particles are amorphous. The tungsten oxide nanoparticles are synthesized by thermal decomposition of ammonium metatungstate hydrate in 
oleylamine and by varying the ammonium metatungstate hydrate concentration, the nanoparticle size, shape and structure can be controlled. At low concentrations, nanoparticles with a diameter of 2-4 $\mathrm{nm}$ form and adopt an amorphous structure that locally resembles the structure of polyoxometalate clusters. When the concentration is increased the nanoparticles become elongated and form nanocrystalline rods up to $50 \mathrm{~nm}$ in length. The study thus reveals a size-dependent amorphous structure when going to the nanoscale and provides further knowledge on how metal oxide crystal structures changes at extreme length scales.

\section{Introduction}

For decades, nanoscientists have studied how nanosizing materials can alter and enhance their functional properties. ${ }^{1-7}$ The size-dependent properties of many materials relate to both increased surface area and changes in electronic and magnetic structure, and advances in nanomaterial synthesis means that some nanomaterials can be precisely produced for specific applications..$^{6,8-11}$ However, the effect of nanosizing on the atomic structure in many nanomaterials is not wellunderstood, and the atomic structure of a nanoparticle is often assumed to be a cutout of the corresponding bulk material..$^{8,12}$ Nevertheless, nanosizing can induce significant changes in atomic structure,,$^{2,13-16}$ and the impact of the particle size on atomic structure varies widely with material type and structure. For $\mathrm{ZrO}_{2}$ nanoparticles, for example, small particle size has been reported to lead to stabilization of the technologically important tetragonal and cubic crystal structures rather than the bulk monoclinic structure ${ }^{17,18} \mathrm{In} \mathrm{MoO}_{2}$, nanosizing leads to defects in the rutile structure, inducing disordered shear-planes, ${ }^{19}$ and many metallic nanoparticles are known to take structures different from bulk $f c c$ and $h c p$ structures such as icosahedral and decahedral motifs ${ }^{20-22}$ However, despite the massive interest in nanomaterials, very few studies have systematically investigated 
the size-structure relationship in nanomaterials. ${ }^{2}$ This limited knowledge can likely be attributed to the challenges of characterizing the atomic structure of nanomaterials. The small size and related atomic disorder make it difficult to extract structural information using e.g. X-ray powder diffraction (XRD) and transmission electron microscopy (TEM). However, these issues can be overcome by applying high-energy X-rays to perform Total Scattering experiments together with Pair Distribution Function analysis. ${ }^{2}$ The intuitive structural interpretation of the PDF makes it possible to characterize complicated nanostructures based on simple models.

In this paper, we present a systematic investigation of size-dependent atomic structure in tungsten oxide nanoparticles. The structural chemistry of bulk tungsten oxides is very rich and diverse, which has led to a large number of applications, for example in catalysis, ${ }^{23,24}$ supercapacitors, ${ }^{25,26}$ optical devices ${ }^{27-30}$ and gas-sensors. ${ }^{31-34}$ Bulk tungsten oxides can be considered built from $\left[\mathrm{WO}_{6}\right]$-octahedra with $\mathrm{W}$ mostly in oxidation state $4+, 5+$, and $6+$. Two $\mathrm{WO}_{2}$ crystal structures are known: a monoclinic distorted rutile structure and a high-pressure orthorhombic structure. ${ }^{35,36}$ The phase diagram of tungsten oxides containing $\mathrm{W}^{5+}$ and $\mathrm{W}^{6+}$ is considerably more complex and at least eight different crystalline polymorphs are known for fully oxidized $\mathrm{WO}_{3} \cdot{ }^{37-40} \mathrm{Six}$ of them are based on the corner-sharing network of the cubic $\mathrm{ReO}_{3}$ structure, but due to distortions in the $\left[\mathrm{WO}_{6}\right]$-octahedra, phases form with symmetries ranging from cubic to triclinic. ${ }^{37,38}$ A monoclinic, $\mathrm{ReO}_{3}$-based $\mathrm{WO}_{3}$ structure is seen in Figure 1A. Additionally, at least two hexagonal $\mathrm{WO}_{3}$ phases are also known, where the $\left[\mathrm{WO}_{6}\right]$-octahedra form a layered structure of hexagonal columns. ${ }^{37-40}$ Upon partial reduction of $\mathrm{W}^{6+}$ to $\mathrm{W}^{5+}$ several different $\mathrm{WO}_{\mathrm{x}}$ phases $(2<\mathrm{x}<3)$, can form such as $\mathrm{W}_{10} \mathrm{O}_{29}\left(\mathrm{WO}_{2.9}\right)$ and $\mathrm{W}_{18} \mathrm{O}_{49}\left(\mathrm{WO}_{2.72}\right) \cdot{ }^{37,38}$ In general these structures form through the formation of shear-planes or bipyramidal pentagonal columns in the $\mathrm{ReO}_{3}$-type structure, as illustrated in Figure $1 \mathrm{~B}\left(\mathrm{~W}_{10} \mathrm{O}_{29}\right)$ and Figure $1 \mathrm{C}\left(\mathrm{W}_{18} \mathrm{O}_{49}\right){ }^{37,38}$ The more reduced the 
compound is, the more shear-planes or bipyramidal pentagonal columns are formed. ${ }^{37,38}$ Tungsten oxides also form several hydrates, such as the $\mathrm{WO}_{3} \cdot 0.3 \mathrm{H}_{2} \mathrm{O}$ in Figure $1 \mathrm{D}$, as well as tungsten bronzes, which are tungsten oxides with intercalated cations..$^{37,38}$
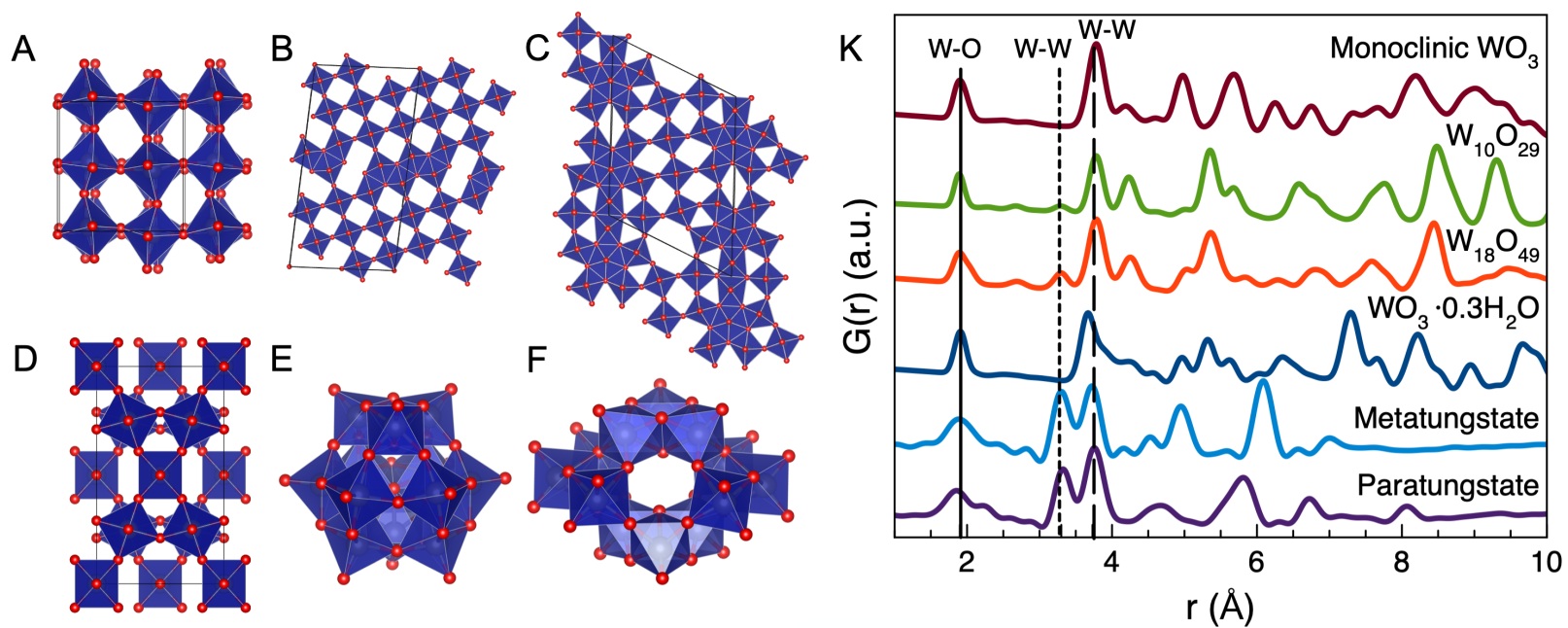

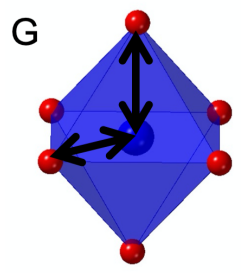

$\mathrm{W}-\mathrm{O}$

$\sim 1.8-2.5 \AA$
$\mathrm{H}$

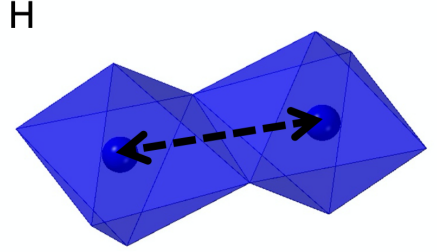

W-W (edge-sharing)

$\sim 3.3 \AA$
I

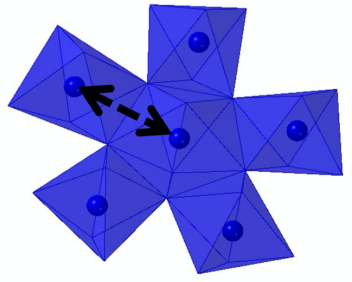

W-W (edge-sharing) $\sim 3.3 \AA$

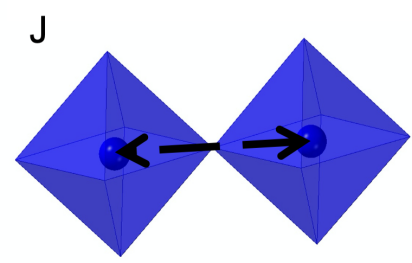

W-W (corner-sharing) $\sim 3.7-3.9 \AA$

Figure 1: Overview of some tungsten oxide compounds and important inter-atomic distances. (A)(F) show 6 examples of tungsten oxide compound structures. The structures are (A) monoclinic $\mathrm{WO}_{3}$, (B) $\mathrm{W}_{10} \mathrm{O}_{29}$, (C) $\mathrm{W}_{18} \mathrm{O}_{49}$, (D) $\mathrm{WO}_{3} \cdot 0.3 \mathrm{H}_{2} \mathrm{O}$, (E) the metatungstate ion $\left[\mathrm{H}_{2} \mathrm{~W}_{12} \mathrm{O}_{40}\right]^{6-}$, and (F) the paratungstate ion $\left[\mathrm{H}_{2} \mathrm{~W}_{12} \mathrm{O}_{42}\right]^{10-}$. $(\mathrm{G})-(\mathrm{J})$ shows the fundamental interatomic distances in tungsten oxide compounds. The first distance $(\mathrm{G})$ is $\mathrm{W}-\mathrm{O}$ bonds. The second distance $(\mathrm{H})$ is a W$\mathrm{W}$ distance which occurs between two edge-sharing [ $\left.\mathrm{WO}_{6}\right]$-octahedra and (I) between a $\left[\mathrm{WO}_{6}\right]$ octahedron and a bipyramidal pentagonal column . The third distance $(\mathrm{J})$ is the $\mathrm{W}-\mathrm{W}$ distance between two corner-sharing $\left[\mathrm{WO}_{6}\right]$-octahedra. $\mathrm{W}$ is shown in blue, $\mathrm{O}$ in red, and $\mathrm{H}$ is omitted for clarity. In $(\mathrm{H}),(\mathrm{I})$, and $(\mathrm{J}), \mathrm{O}$ is also omitted for clarity. $(\mathrm{K})$ shows the calculated PDFs for the structures seen in (A)-(F). The vertical lines indicate the 3 fundamental distances in the tungsten oxide compounds shown in (G-J). 
The complexity of solid-state tungsten oxide structures is mirrored by the structure of tungsten oxide compounds in solution. In solution, tungstates can form polyoxometalates (POMs), which are large polyanions built from corner- and edge-sharing $\left[\mathrm{WO}_{6}\right]$-octahedra. Unlike the crystalline structures, edge-sharing octahedra are also present when $\mathrm{W}$ is in oxidation state $6+$, as seen for example in the metatungstate ion $\left[\mathrm{H}_{2} \mathrm{~W}_{12} \mathrm{O}_{40}\right]^{6-}$ which adopts the well-known Keggin cluster structure as seen in Figure 1E. It is common for POMs to contain almost equal amounts of edgesharing and corner-sharing octahedra, as also seen for paratungstate $\mathrm{B}\left[\mathrm{H}_{2} \mathrm{~W}_{12} \mathrm{O}_{42}\right]^{10-}$ in Figure 1E. ${ }^{41}$

The basic building block of all these compounds are corner- and edge-sharing $\left[\mathrm{WO}_{6}\right]$-octahedra. If considering their local atomic structure, they give rise to 3 basic interatomic distances, which are depicted in Figure 1G-J. W-O distances in oxides are reported to be approximately 1.8-2.5 , depending on geometry and oxidation states (Figure 1G), and the W-W distance between two corner-sharing $\left[\mathrm{WO}_{6}\right]$-octahedra is around 3.7-3.9 $\AA$ (Figure 1J). A W-W distance between two edge-sharing $\left[\mathrm{WO}_{6}\right]$-octahedra $($ Figure $1 \mathrm{H})$ or between a $\left[\mathrm{WO}_{6}\right]$-octahedron and a $\left[\mathrm{WO}_{7}\right]$ bipyramidal pentagon (Figure 1I) is approximately $3.3 \AA$. In $\mathrm{WO}_{2}$, however, the distance is considerably shorter and can be between 2.5-3.1 $\AA^{35,36}$ Figure $1 \mathrm{~K}$ illustrates the calculated PDFs of the 6 structures shown in Figure 1B-F. As can be seen, PDF is a powerful way of characterizing and distinguishing between structures of tungsten oxide compounds, both in the crystalline form and as polyoxometalate nanoclusters. The relative amount of edge-sharing $\left[\mathrm{WO}_{6}\right]$-octahedra (the peak at $r=3.3 \AA$ ) compared to corner-sharing $\left[\mathrm{WO}_{6}\right]$-octahedra (peak at $\mathrm{r}=3.8 \AA$ ) shows the differences between various POMs and crystalline tungsten oxides in a straightforward way. PDF has previously been applied for studies of amorphous and nanostructured tungsten oxides. For example, Lugovskaya et al ${ }^{42}$ found that an amorphous tungsten oxide had a local structure similar to $\mathrm{WO}_{3} \cdot 0.3 \mathrm{H}_{2} \mathrm{O}$ (Figure 1D), while Jürgen et al. ${ }^{43}$ found that their sample of amorphous tungsten 
oxide had a structure unlike any crystalline tungsten oxides with much lower W-O coordination number and direct $\mathrm{W}-\mathrm{W}$ bonding.

The diverse structural chemistry of bulk tungsten oxides is thus well known, and we here study the effects of nanoparticle size on the tungsten oxide crystal structure. Based on a synthesis method first reported by Soultandis et al. ${ }^{44}$ we synthesize nanomaterials with different particle sizes, and use a combination of PDF analysis, TEM, and Small-Angle X-ray Scattering (SAXS) for characterization. We show that the particle size and morphology can be controlled by changing the initial precursor concentration. At lower concentrations, the synthesis yields ultra-small tungsten oxide nanoparticles with an amorphous structure whose local structure is unlike any known crystalline tungsten oxide. By increasing the concentration, the size of the nanoparticles increases, and the particles become crystalline. While amorphous nanoparticles are well known, this is the first time, to the best of our knowledge, that the amorphous structure is shown to be a direct consequence of nanoparticle size.

\section{Results and Discussion}

Five samples of tungsten oxide nanoparticles were prepared by thermal decomposition of ammonium metatungstate hydrate (AMT) in oleylamine at $250{ }^{\circ} \mathrm{C}$ with varying precursor concentrations. Figure 2A shows X-ray scattering patterns obtained from the 5 samples. The scattering patterns from the two samples prepared with the lowest precursor concentrations show only a few broad features which are consistent with very small or disordered nanoparticles. The three samples prepared with higher concentrations give rise to at least one Bragg peak and a few other broader features in their scattering patterns. To better study the structure, we turn to PDF analysis of the data. The PDFs obtained from the samples are shown in Figure 2B. Again, we see 
a clear difference between the samples synthesized with low AMT concentrations ( 5 and $10 \mathrm{mM}$ ) and the samples synthesized with high AMT concentrations (15, 20, and $25 \mathrm{mM})$. In the PDFs from the lower concentration samples, clear peaks extend to only $r \approx 8 \AA$. As opposed to bulk tungsten oxides they appear to contain a larger amount of edge-sharing octahedra than cornersharing octahedra, as the peak at $r=3.3 \AA$ is more intense than the peak at $r=3.8 \AA$. In the PDFs obtained from the samples synthesized with $15 \mathrm{mM}, 20 \mathrm{mM}$ and $25 \mathrm{mM}$ precursor concentrations, clear peaks extend beyond $r=10 \AA$ as expected for materials showing Bragg peaks. The PDFs are plotted to their full range in Figure S1. The increase in size and order can only be related to the increase in concentration as all other synthetic parameters are identical in the 5 syntheses.
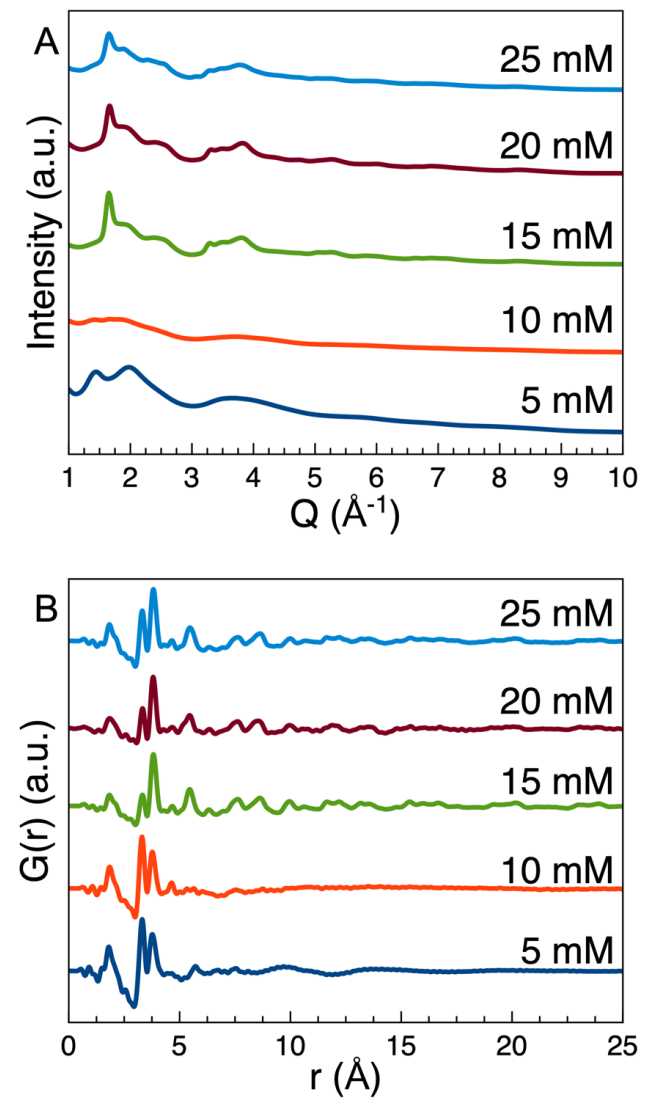

Figure 2: (A) The total scattering data of the 5 samples studied. In the 15, 20, and $25 \mathrm{mM}$ samples a Bragg peak is visible at $1.65 \AA^{-1}$. (B) The resulting PDFs from the data in (A). 
Before further analysis of the atomic structure of the nanoparticles, we first characterize the particle size and size distribution using Small-Angle X-ray Scattering (SAXS). SAXS data were measured for the 5 and $10 \mathrm{mM}$ samples. The nanoparticles aggregated very quickly and if left undisturbed they packed into a well-ordered nanoscale lattice as seen in Figure S2. However, SAXS data collected immediately after sample preparation before the formation of a nanoparticle lattice could be modeled using a spherical form factor with a lognormal size distribution, the hardsphere structure factor formulated in $\mathrm{SASview}^{45}$ and a power law to describe the aggregation of nanoparticles. ${ }^{46-48}$ Further details on the model and the parameters used are given in the SI. The SAXS data show that the nanoparticles synthesized with $5 \mathrm{mM}$ precursor concentration (Figure $3 \mathrm{~A}$ ) are on average $2 \mathrm{~nm}$ in diameter which is consistent with the size reported by Soultanidis et al ${ }^{44}$ Analysis of the SAXS data from the samples synthesized with $10 \mathrm{mM}$ precursor concentration show a particle size of ca. $4 \mathrm{~nm}$ in diameter (Figure 3B).

In Figure 3C the PDFs for the two samples are plotted with an indication of the size obtained from SAXS. If the particles were nanocrystalline and had an ordered structure, we would expect to see clear PDF peaks to almost this r-value, taking into account instrumental PDF damping. The difference between the extent of atomic ordering as investigated by PDF and the particle size obtained from SAXS modelling means that the atomic structure of the nanoparticles cannot be nanocrystalline. Instead, they appear amorphous, as also indicated by the broad features in the PDFs at ca. $r=10 \AA$. 

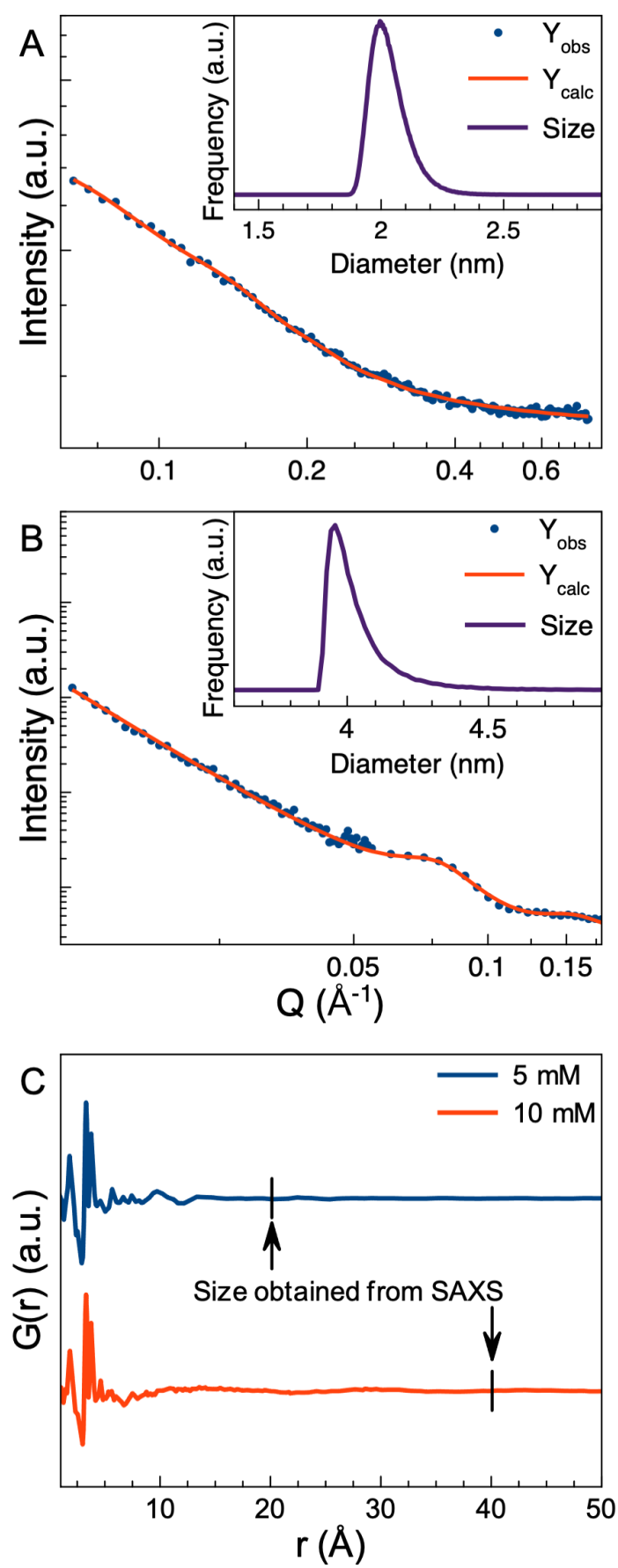

Figure 3: SAXS data for the 5 (A) and $10 \mathrm{mM}$ (B) samples together with calculated SAXS patterns for $2 \mathrm{~nm}$ (A) and $4 \mathrm{~nm}$ (B) spherical nanoparticles with particle-particle interactions described using a hard-sphere structure factor. The inserts show the corresponding lognormal size distributions. All SAXS data are plotted on a double logarithmic scale. (C) The PDF for the two samples with the SAXS size indicated, compared to the degree of ordering in the PDFs. 


\section{Structural characterization of amorphous samples}

PDF analysis allows identifying the main structural motifs present in amorphous materials with only local atomic order. Considering the PDFs shown in Figure 2B, the first peak in the PDFs from all samples can be assigned to the W-O bond at $\mathrm{r}=1.8 \AA$ which indicates $\left[\mathrm{WO}_{6}\right]$-octahedra with $\mathrm{W}^{5+}$ or $\mathrm{W}^{6+}$. The two next peaks are at $\mathrm{r}=3.3 \AA$ and $\mathrm{r}=3.8 \AA$ which is the $\mathrm{W}-\mathrm{W}$ distances expected for structures containing $\mathrm{W}^{5+}$ or $\mathrm{W}^{6+}$ as discussed above. In the amorphous nanoparticles (5 and 10 $\mathrm{mM}$ samples) the peak at $3.3 \AA$ arising from edge-sharing $\left[\mathrm{WO}_{6}\right]$-octahedra is more prominent compared to the $3.8 \AA$ peak from corner-sharing $\left[\mathrm{WO}_{6}\right]$-octahedra. This trend is not observed in crystalline tungsten oxides as illustrated in the calculated PDFs shown in Figure 1. In a study of amorphous tungsten oxide films prepared by thermal evaporation, Lugovskaya et al. ${ }^{42}$ used PDF for structure characterization and did not observe any significant intensity at $r=3.3 \AA$ as opposed to the nanoparticles reported here. Jürgen et al. ${ }^{43}$ observed a W-W PDF peak at $2.5 \AA$ from a tungsten oxide thin film prepared using rf sputtering, which we do not observe in our samples. The structure of the nanoparticles studied here thus appears different than any previously reported crystalline or amorphous tungsten oxides.

The intense PDF peak at $r=3.3 \AA$ indicates that the structure of the nanoparticles may resemble that found in POMs. The precursor for the synthesis, ammonium metatungstate hydrate, contains the metatungstate ion $\left[\mathrm{H}_{2} \mathrm{~W}_{12} \mathrm{O}_{40}\right]^{6-}$ (Figure 1E), but, as seen in Figure 4A, the metatungstate cluster structure does not describe the PDF from the amorphous particles well. We have previously studied the formation of tungsten oxides nanomaterials, showing that metatungstate converts into the paratungstate $\mathrm{B}$ ion, $\left[\mathrm{H}_{2} \mathrm{~W}_{12} \mathrm{O}_{42}\right]^{10-}$ (Figure $1 \mathrm{E}$ ) when heated in oleylamine. ${ }^{49}$ When using the paratungstate B cluster structure as model, a better agreement with the experimental PDF is seen as illustrated in Figure 4B. The paratungstate contains interatomic distances that nicely overlap with the peak positions up to $7 \AA$ in the PDF from the $5 \mathrm{mM}$ sample. However, the intensities of 
the peaks in the PDF of paratungstate B do not match the experimental PDF. As can be seen in the fit in Figure 4B, the nanoparticles contain more edge-sharing [ $\left.\mathrm{WO}_{6}\right]$-octahedra compared to corner-sharing $\left[\mathrm{WO}_{6}\right]$-octahedra, as the peak at $\mathrm{r}=3.3 \AA$ is more intense than the peak at $\mathrm{r}=3.8$ $\AA$. In the paratungstate $\mathrm{B}$ cluster, this is reversed with the peak at $r=3.8 \AA$ as the most intense peak, also seen in Figure 4B. The local structure of the amorphous nanoparticles is therefore similar to the atomic structure of the paratungstate cluster but more disordered and with fewer corner-sharing octahedra.

To obtain a better fit, we therefore altered the paratungstate model. By systematically removing $\left[\mathrm{WO}_{6}\right]$-octahedra from the paratungstate cluster and fitting the resulting fragment structure to the experimental PDF we are able to identify which motifs are present in the amorphous structure. The fragments were fitted by refining a scale factor, a single atomic displacement parameter (ADP) for the $\mathrm{W}$ atoms $\left(\mathrm{U}_{\mathrm{iso}, \mathrm{w}}\right)$ and a single $\mathrm{ADP}$ for the $\mathrm{O}$ atoms $\left(\mathrm{U}_{\mathrm{iso}, \mathrm{w}}\right)$. Afterwards the $\mathrm{W}$ atomic positions were refined but constrained not to move more than $0.05 \AA$ along the $\mathrm{x}, \mathrm{y}$, and $\mathrm{z}$-directions. The structures that best describe the PDF from the $5 \mathrm{mM}$ sample contain around 6-8 [ $\left.\mathrm{WO}_{6}\right]$ octahedra. Figure $4 \mathrm{C}$ shows a fit of the one of the fragments which is built up from 7 [ $\mathrm{WO}_{6}$ ] octahedra. Clusters containing 6 or 8 octahedra also gave a good fit to the experimental PDF as seen in Figure S3 and S4. Figure S5 show an example of fits using a model with only 4 octahedra which does not give enough intensity to the edge-sharing peak compared to the experimental PDF of the $5 \mathrm{mM}$ sample. The well-fitting structures all contain a "triad" of edge-sharing $\left[\mathrm{WO}_{6}\right]$-octahedra as their central motifs, as marked in green in Figure 4D, 4E, and 4F. The remaining octahedra are all corner-sharing with the triad, and edge- or corner-sharing with each other.

The PDF from the $10 \mathrm{mM}$ sample could be described in the same way. However, the structure of this sample appears more disordered than that synthesized with $5 \mathrm{mM}$ precursor concentration, 
as no clear PDF peaks are seen at r-values above $6 \AA$ (Figure 3C). This is also reflected in the PDF fitting, illustrated in Figure S6. The best model identified for the $10 \mathrm{mM}$ sample contain only 5 octahedra, however, the triad motif is again significant for obtaining a good fit.

It is here important to note that the models presented should not be considered unique structure solutions to the two samples. Instead, they are simple representations of the dominant structural motifs present. The models thus show that the atomic structure of the smallest tungsten oxide nanoparticles is an amorphous network based on triads of edge-sharing $\left[\mathrm{WO}_{6}\right]$-octahedra, commonly found in POMs, connected through corner-sharing $\left[\mathrm{WO}_{6}\right]$-octahedra. 


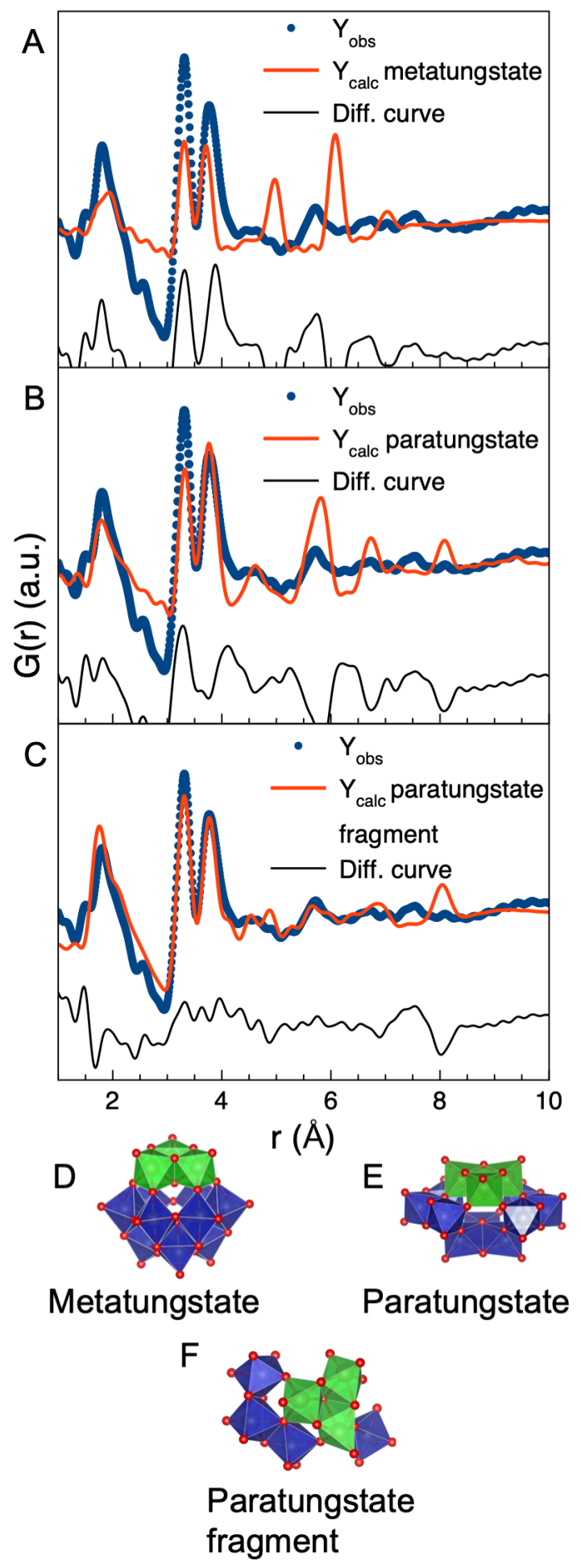

Figure 4: (A) The fit of metatungstate (structure shown in D) to the PDF obtained from the $5 \mathrm{mM}$ sample. (B) The fit of paratungstate (structre shown in E) to the PDF obtained from the $5 \mathrm{mM}$ sample. (C) The fit of the structure seen in (F) to the PDF obtained from the $5 \mathrm{mM}$ sample. The triad in green highlights the common motif in the POMs that describe the local structure of the amorphous nanoparticles. 


\section{Structural characterization of nanocrystalline nanoparticles}

The samples synthesized with high AMT concentrations $(15,20$, and $25 \mathrm{mM})$ all show a single, clear Bragg peak at approximately $\mathrm{Q}=1.65 \AA^{-1}$ (corresponding to a d-spacing $=3.8 \AA$ ) while the remaining features are broad. Similar scattering patterns have been reported for a range of different tungsten oxide nanomaterials. ${ }^{44,50-54}$ However as shown in Figure 5A, Bragg peaks and d-spacings in this range occur in almost all reported $\mathrm{WO}_{\mathrm{x}}$ crystal structures, and we therefore cannot identify the crystalline phase from this information alone. We therefore again turn to PDF analysis.

Before further discussing the PDFs obtained from the 15, 20, and $25 \mathrm{mM}$ samples, we address the nanoparticle size and shape using TEM. Figure 5 shows TEM images from the samples synthesized using $15 \mathrm{mM}$ (Figure 5B) and $20 \mathrm{mM}$ (Figure 5C) precursor concentration, which confirm that the nanoparticles synthesized at high concentrations are nanorods. The size of the nanorods is not very uniform. The smallest nanorods are observed in the $20 \mathrm{mM}$ sample and are only $1 \mathrm{~nm}$ wide and $5 \mathrm{~nm}$ long. In the $15 \mathrm{mM}$ sample, however, we observe rods that are $5 \mathrm{~nm}$ wide and up to $50 \mathrm{~nm}$ long. This is consistent with the PDF results where clear peaks extend the furthest into $r$ in the PDF obtained from the nanoparticles synthesized at $15 \mathrm{mM}$. However, in all the samples most of the nanorods are between $2 \times 15 \mathrm{~nm}$ to $4 \times 20 \mathrm{~nm}$. Additional TEM images from the samples synthesized at 15,20 and $25 \mathrm{mM}$ as well as nanoparticles synthesized at $25 \mathrm{mM}$ at $300{ }^{\circ} \mathrm{C}$ for $3 \mathrm{~h}$ are presented in Figure S7-S10, which all show the same features. 

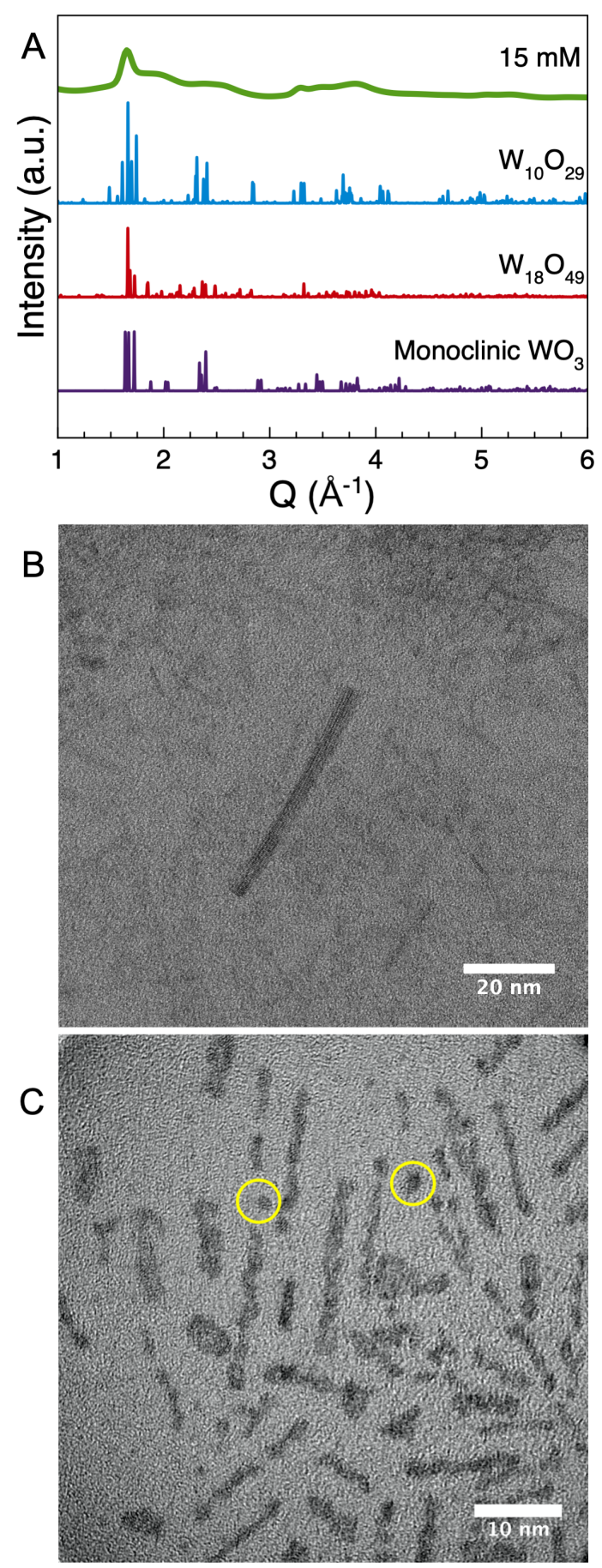

Figure 5: (A) Comparison of the diffraction pattern obtained from the $15 \mathrm{mM}$ sample to the calculated diffraction pattern from $\mathrm{W}_{10} \mathrm{O}_{29}, \mathrm{~W}_{18} \mathrm{O}_{49}$ and $\mathrm{m}-\mathrm{WO}_{3}$. The one Bragg present in the data arise from most tungsten oxide crystal structures. (B) TEM image of a nanorod from the $15 \mathrm{mM}$ sample. (C) TEM image the $20 \mathrm{mM}$ sample, showing nanorods. Some spherical nanoparticles are also visible, marked with yellow circles. 
We start our structural analysis of the high concentration samples by considering the PDF obtained from the $15 \mathrm{mM}$ sample. The first three main peaks are at $\mathrm{r}=1.8 \AA, 3.3 \AA$ and $3.8 \AA$, which corresponds to the W-O distance, the W-W in edge-sharing octahedra/pentagonal bipyramids and the W-W distance corner-sharing octahedra. The presence of the peak at $3.3 \AA$ shows that the sample cannot be described by any of the known $\mathrm{WO}_{3}$ phases, as they do not contain any edge-sharing $\left[\mathrm{WO}_{6}\right]$-octahedra or $\left[\mathrm{WO}_{7}\right]$-pentagonal bipyramids. As shown in Figure S11 $\mathrm{WO}_{2}$ also cannot describe the experimental PDF. Instead, the atomic structure of the nanorods appear to resemble the $\mathrm{WO}_{\mathrm{x}}(2<\mathrm{x}<3)$ crystal structures. Figure 6 and Figure S12-S17 show fits to the PDF using the different $\mathrm{WO}_{\mathrm{x}}$ crystal structures reported in the literature. Each fit is performed by refining the scale factor, unit cell parameters, the atomic positions of the $\mathrm{W}$ atoms constrained by the symmetry of the reported crystallographic space group, and a spherical crystallite size. An isotropic ADP value $\left(\mathrm{U}_{\mathrm{iso}, \mathrm{w}}\right)$ for all $\mathrm{W}$ atoms, an isotropic $\mathrm{ADP}$ value for all $\mathrm{O}$ atoms $\left(\mathrm{U}_{\mathrm{iso}, \mathrm{O}}\right)$, and a parameter to describe correlated atomic motion $\left(\delta_{2}\right)$ were also refined. The reported tungsten oxide phases that best describe the experimental PDF are those which contain bipyramidal pentagonal columns, for example $\mathrm{W}_{18} \mathrm{O}_{49}$ as shown in Figure 6A. Phases that instead contain shearplanes such as $\mathrm{W}_{10} \mathrm{O}_{29}$ fail to provide a good description of the PDF as shown in Figure 6B.

While the structures containing bipyramidal pentagonal columns account for all PDF peaks, they fail to accurately describe the intensities of the $3.3 \AA$ and 3.8 peaks. Furthermore, the $\mathrm{U}_{\text {iso,.o }}$ parameter refine to the unphysical value of $0.1 \AA^{2}$ or above. In the fits shown, the $\mathrm{U}_{\text {iso,oo }}$ value has been fixed to $0.05 \AA^{2}$. The high ADP value for $\mathrm{O}$ indicates a high degree of oxygen disorder in the structure. To see if it was possible to further improve the description of the experimental PDF, we investigated crystal systems with similar crystal structures as $\mathrm{WO}_{\mathrm{x}}(2<\mathrm{x}<3)$ containing shear planes or pentagonal columns, such as $\mathrm{MoO}_{\mathrm{x}}, \mathrm{NbO}_{\mathrm{x}}, \mathrm{MoNbO}_{\mathrm{x}}, \mathrm{WNbO}_{\mathrm{x}}$ and $\mathrm{WMoO}_{\mathrm{x}}$. In our modelling 
starting from these phases, all metal atoms were replaced with W. Example fits for all these systems are shown in Figure S18-S25. We found that a good fit of the PDF obtained from the 15 $\mathrm{mM}$ sample could be obtained by using a $\mathrm{Nb}_{2} \mathrm{WO}_{8}$ phase with $\mathrm{Nb}$ exchanged for $\mathrm{W} .{ }^{55}$ When the $\mathrm{Nb}$ atoms are replaced with $\mathrm{W}$, the $\mathrm{Nb}_{2} \mathrm{WO}_{8}$ phase becomes a $\mathrm{W}_{3} \mathrm{O}_{8}$ phase. $\mathrm{W}_{3} \mathrm{O}_{8}$ crystal structures have been reported before, ${ }^{56}$ but none of the reported phases can describe the PDF as shown in Figures S14 and S15. Both the previously reported $\mathrm{W}_{3} \mathrm{O}_{8}$ phases are high-pressure phases with crystal structures that are different from other $\mathrm{WO}_{\mathrm{x}}$ structures with one containing edge-sharing octahedra not formed from shear-planes and the other containing pentagonal bipyramids that are corner-sharing with each other..$^{56}$

As seen in Figure 6C, the W-substituted $\mathrm{Nb}_{2} \mathrm{WO}_{8}$ structure can accurately describe the ratio of the $\mathrm{r}=3.3 \AA$ and $\mathrm{r}=3.8 \AA$ peaks, while also simultaneously describing the PDF up to $20 \AA$ as shown in Figure 7A. Other phases such as $\mathrm{Mo}_{9} \mathrm{O}_{26}$ also have the correct ratio of edge/cornersharing octahedra but cannot describe the structure beyond $8 \AA$, see Figure S18. Furthermore, the $\mathrm{U}_{\text {iso, }, \mathrm{O}}$ value of the $\mathrm{W}$-substituted $\mathrm{Nb}_{2} \mathrm{WO}_{8}$ phase refine to the much more physical value of 0.01 $\AA^{2}$, suggesting that the $\mathrm{W}$-substituted $\mathrm{Nb}_{2} \mathrm{WO}_{8}$ phase much better describes the $\mathrm{O}$ disorder present in the nanoparticles synthesized at $15 \mathrm{mM}$. The W-substituted $\mathrm{Nb}_{2} \mathrm{WO}_{8}$ crystal structure distinguishes itself from other bipyramidal pentagonal columns containing crystal structures by being one of the few phases where all octahedra are part of a bipyramidal pentagonal column. This gives it a high number of W-W distances at $3.3 \AA$ compared to the W-W distances at $3.7 \AA$. Other examples of such phases are one of the previously reported $\mathrm{W}_{3} \mathrm{O}_{8}$ phases ${ }^{56}$ and a $\mathrm{Nb}_{22} \mathrm{~W}_{20} \mathrm{O}_{102}$ phase,${ }^{57}$ but none of these phases have their polyhedra arranged in a way that describe the PDF as shown in Figures $\mathrm{S} 15$ and $\mathrm{S} 22$. In the original $\mathrm{Nb}_{2} \mathrm{WO}_{8}$ structure, the $\mathrm{Nb}$ and $\mathrm{W}$ atoms are distributed across all metal sites which we interpret as mixed occupancy of $\mathrm{W}^{5+}$ and $\mathrm{W}^{6+}$ on the 
metal sites. The $\mathrm{W}$-substituted $\mathrm{Nb}_{2} \mathrm{WO}_{8}$ phase is shown alongside the $\mathrm{W}_{18} \mathrm{O}_{49}$ and the $\mathrm{W}_{10} \mathrm{O}_{29}$ in Figure 6D-F and the refined parameters for the fits in Figure 6 are seen in Table S3-S5.

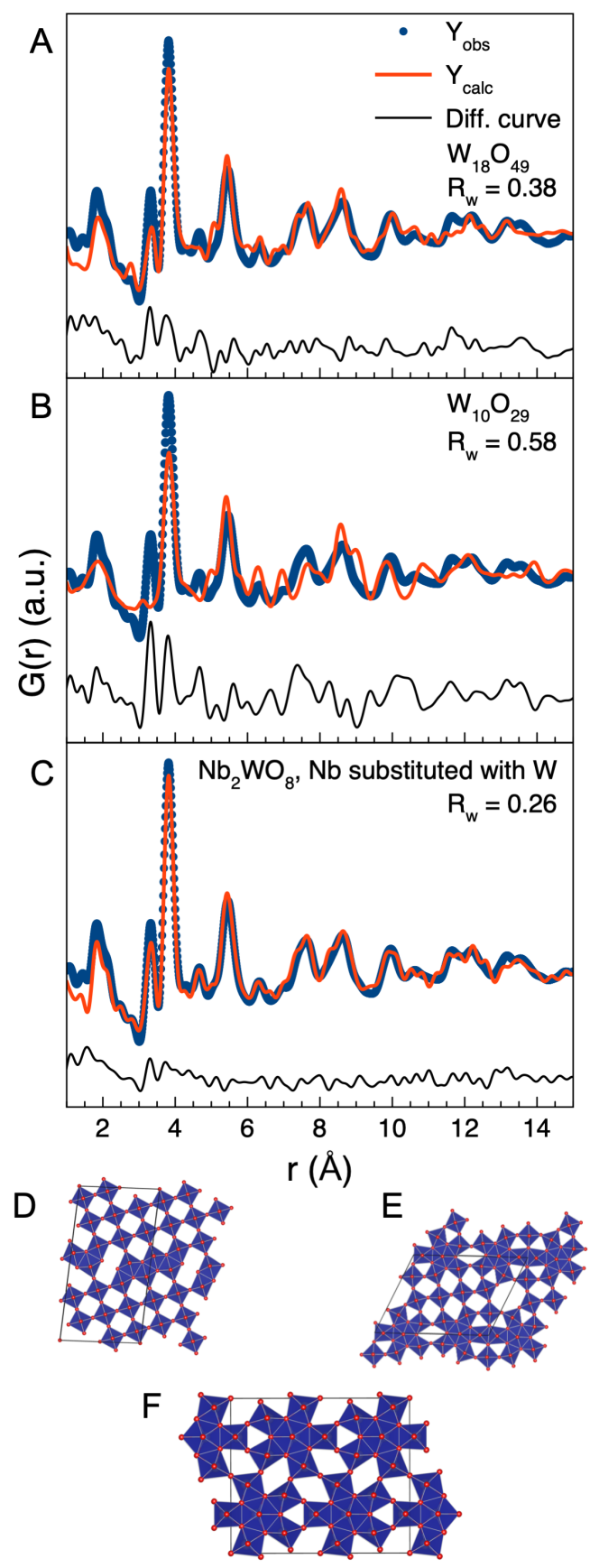

Figure 6: The fits of $\mathrm{W}_{10} \mathrm{O}_{29}(\mathrm{~A}), \mathrm{W}_{18} \mathrm{O}_{49}(\mathrm{~B})$, and $\mathrm{W}_{3} \mathrm{O}_{8}(\mathrm{C})$ based on a $\mathrm{Nb}_{2} \mathrm{WO}_{8}$ structure, with all $\mathrm{Nb}$ substituted with $\mathrm{W}$, to the PDF obtained from the $15 \mathrm{mM}$ sample. (D) The refined unit cell from $(\mathrm{C})$ viewed along the crystallographic a-axis. 
The PDF from the $15 \mathrm{mM}$ sample was also fitted over a longer range $(\mathrm{r}=1-40 \AA)$ in order to obtain information more information on the morphology of the particles. When using a simple model, where the size-dependent dampening of the PDF is described with a spherical envelope we obtain an average diameter of $23 \AA$ as show in Figure 7A. However, this spherical particle model cannot describe the elongated shape of the nanoparticles and therefore does not account for the PDF peaks seen at the highest r-values. The fit reveals that the peaks that are not fitted when using this simple approach are spaced with a repeating distance of $3.8 \AA$. This is exactly the height of a $\left[\mathrm{WO}_{6}\right]$ or $\left[\mathrm{WO}_{7}\right]$ unit, as shown in Figure 7A. The unit cell parameters of the $\mathrm{W}$-substituted $\mathrm{Nb}_{2} \mathrm{WO}_{8}$ phase refines to $\mathrm{a}=3.82 \AA, \mathrm{b}=18.46 \AA$ and $\mathrm{c}=16.06 \AA$ which indicates that the repeating distance of $3.8 \AA ̊$ occurring beyond $23 \AA$ is due to the unit cells stacking on top of each other to form the nanorod. As shown in Figure S26 the calculated diffraction pattern from the refined cell fits well with the measured scattering pattern. The intense Bragg peak observed in the measured data arise due to the (100) plane in the $\mathrm{W}$-substituted $\mathrm{Nb}_{2} \mathrm{WO}_{8}$ structure which show that the nanorods grow along the $<100>$ direction. The PDF peaks seen above $23 \AA$ therefore primarily represent interatomic distances along the $<100>$ direction. From the PDF refinements, we can therefore estimate the diameter of the nanorods (size along $<010>$ and $<001>$ ) to be ca. $20-25 \AA$. Here, it should be noted that the size of the $\mathrm{W}$-substituted $\mathrm{Nb}_{2} \mathrm{WO}_{8}$ unit cell is $\mathrm{b}=18.46 \AA$ and $\mathrm{c}=16.06$ $\AA$, i.e. in the same size-range as the estimated particle width. We do not interpret the nanorods as having a perfectly well-defined $\mathrm{Nb}_{2} \mathrm{WO}_{8}$ crystal structure, but rather that this structure contains the correct $\left[\mathrm{WO}_{6}\right]$-octahedra and $\left[\mathrm{WO}_{7}\right]$ arrangement and therefore describes the experimental PDF. 
In Figure 7B, we compare the PDFs obtained from the 15, 20, and $25 \mathrm{mM}$ samples, i.e. the samples containing nanorods. The PDFs show similar features, except for the increasing intensity of the $r$ $=3.3 \AA$ peak with increasing AMT concentration. This indicates an increase in the amount of edgesharing $\left[\mathrm{WO}_{6}\right]$-octahedra or $\left[\mathrm{WO}_{7}\right]$-pentagonal bipyramidal columns in the samples synthesized with higher precursor concentration. Figure $7 \mathrm{C}$ shows a fit to the PDF from the $25 \mathrm{mM}$ samples using the $\mathrm{W}$-substituted $\mathrm{Nb}_{2} \mathrm{WO}_{8}$ structure. The model describes all features in the PDF except for the extra intensity at $3.3 \AA$. A similar fit is obtained for the $20 \mathrm{mM}$ sample (Figure S27). None of the known tungsten oxide crystal structures can fit the extra intensity at $3.3 \AA$ in the PDFs obtained from the 20 and $25 \mathrm{mM}$ samples. However, as indicated in the TEM image shown in Figure 5C, the $20 \mathrm{mM}$ sample also contains some spherical nanoparticles that are smaller than $4 \mathrm{~nm}$. The presence of nanoparticles with the same amorphous structure as described earlier would explain the relative increase of the peak corresponding to edge-sharing $\left[\mathrm{WO}_{6}\right]$-octahedra. To test this hypothesis, we modelled the PDFs from the $20 \mathrm{mM}$ and $25 \mathrm{mM}$ samples with a 2-phase fit, i.e. the W-substituted $\mathrm{Nb}_{2} \mathrm{WO}_{8}$ crystal structure and a cluster representing the amorphous structure. For simplicity, the amorphous particles were modelled using a single triad with a corner-sharing $\left[\mathrm{WO}_{6}\right]$-octahedra (Figure 7D), i.e. a structure with $4\left[\mathrm{WO}_{6}\right]$ octahedra. The combined fit provides a good description of the PDF of both samples, as seen in Figure S28 and Figure 7D.

The refined parameters obtained for the crystalline phase from modelling of the $15 \mathrm{mM}, 20 \mathrm{mM}$ and $25 \mathrm{mM}$ sample are given in Tables S5-S7. The refined parameters for all three samples are similar, except for the spherical diameter that refines to $23 \AA$ for the $15 \mathrm{mM}$ sample, $19 \AA$ for the $20 \mathrm{mM}$ sample, $17 \AA$ for the $25 \mathrm{mM}$ sample. However, considering the simple modelling and the large polydispersity present in the samples, these differences are not likely to be significant. 

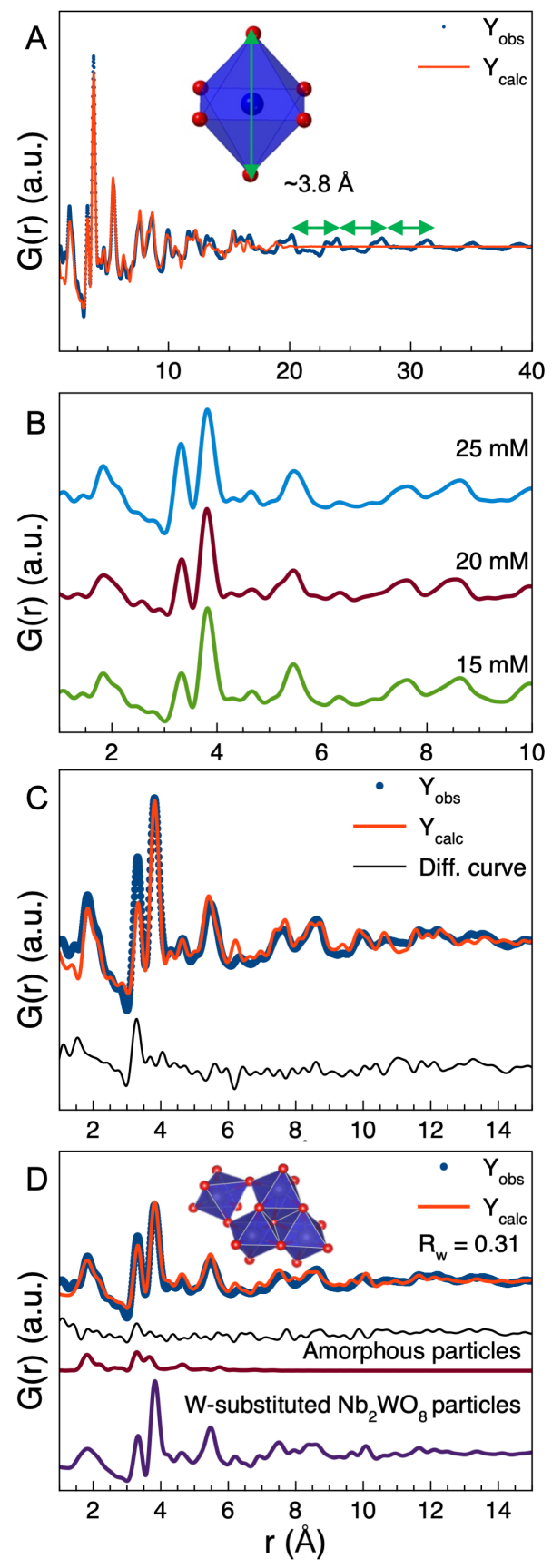

Figure 7: (A) The fit from Figure 6C extended to $r=40 \AA$. The peaks not described by the spherical model are spaced with approximately $3.8 \AA$ between each peak which corresponds to the height of a [ $\left.\mathrm{WO}_{6}\right]$-octahedron. (B) Comparison of the PDFs from the 15, 20, and $25 \mathrm{mM}$ samples where it can be seen that the intensity of the $\mathrm{r}=3.3 \AA$ peak increases as the precursor concentration is increased. (C) The fit of the $\mathrm{W}$-substituted $\mathrm{Nb}_{2} \mathrm{WO}_{8}$ structure to the PDF from the $25 \mathrm{mM}$ sample, where the model cannot fit the $3.3 \AA$ peak. (D) A combined fit with the W-substituted $\mathrm{Nb}_{2} \mathrm{WO}_{8}$ structure and the inserted structure to the PDF from the $25 \mathrm{mM}$ sample. The structure in the insert represents the local structure of the amorphous nanoparticles. The black curve is the difference curve, and below are the relative contributions from the two structures. The refined parameters are seen in Table S6 


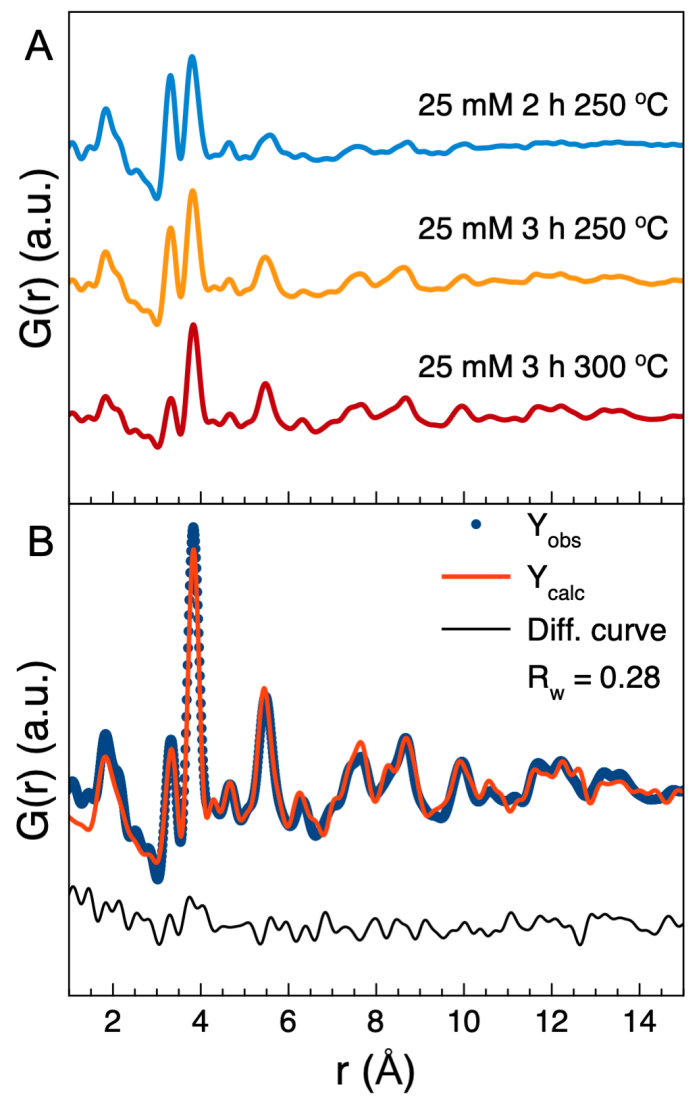

Figure 8: (A) Comparison of PDFs from 3 samples synthesized with $25 \mathrm{mM}$ concentration at 250 or $300{ }^{\circ} \mathrm{C}$ for 2 and $3 \mathrm{~h}$. Increasing the heating time slightly reduces the intensity of the $3.3 \AA$ peak, while increasing the temperature greatly reduces the extra intensity at $r=3.3 \AA$. (B) Fit using the W-substituted $\mathrm{Nb}_{2} \mathrm{WO}_{8}$ phase to the $\mathrm{PDF}$ from the nanoparticles obtained at $300{ }^{\circ} \mathrm{C}$ with a concentration of $25 \mathrm{mM}$ after $3 \mathrm{~h}$ heating.

\section{Heating time and temperature effects}

To investigate the effects of reaction time and temperature on the synthesis, nanoparticles were also synthesized with longer reaction times (increased from $2 \mathrm{~h}$ to $3 \mathrm{~h}$ ) and at higher temperature $\left(300^{\circ} \mathrm{C}\right.$ instead of $\left.250^{\circ} \mathrm{C}\right)$. Figure $8 \mathrm{~A}$ shows PDFs illustrating the effect of these parameters. When keeping a reaction temperature of $250^{\circ} \mathrm{C}$, increasing the heating time only slightly altered the ratio of the peaks at $\mathrm{r}=3.3 \AA$ and $\mathrm{r}=3.8 \AA$ and did not have any major impact on the nanoparticle 
structure. However, increasing the temperature to $300^{\circ} \mathrm{C}$ dramatically reduces the intensity of the $r=3.3 \AA$ peak as seen in Figure 8A. The fit in Figure 8B demonstrates that the nanorods can again be described with the $\mathrm{W}$-substituted $\mathrm{Nb}_{2} \mathrm{WO}_{8}$ structure, without the need for a second phase representing the amorphous particles. The refined parameters are shown in Table S8. The higher temperature thus ensures conversion of the remaining amorphous nanoparticles into crystalline nanorods, while not affecting the atomic structure of the formed nanorods. The spherical diameter refines to $25 \AA$ indicating increased growth of the nanorods.

The conversion of the smaller amorphous nanoparticles into nanorods indicates a formation and growth mechanism of the nanorods based on the amorphous nanoparticles. At low concentrations, only the smaller, amorphous nanoparticles form. At higher concentrations the amount of formed amorphous nanoparticles will be large enough for some of them to meet and form crystalline nanorods. The rods will then grow, possibly through an oriented attachment-like mechanism along the crystallographic $a$-direction by attaching the amorphous nanoparticles to the ends of the nanorods. When a sufficient number of amorphous nanoparticles have formed rods, the number of amorphous nanoparticles becomes too low for further reaction resulting in a mixture of the two types of particles in the sample. By increasing the temperature, it is possible to overcome the possible barrier stopping the remaining amorphous nanoparticles from reacting and convert them to crystalline nanorods. 


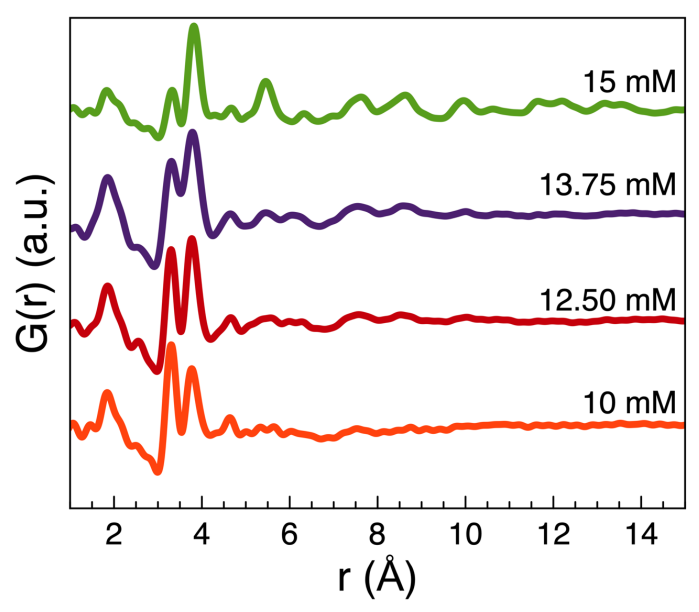

Figure 9: The PDFs obtained from the samples synthesized at 12.50 and $13.75 \mathrm{mM}$ at $250{ }^{\circ} \mathrm{C}$ for $2 \mathrm{~h}$ compared to the PDF of the samples synthesized at 10 and $15 \mathrm{mM} \mathrm{mM}$ at $250{ }^{\circ} \mathrm{C}$ for $2 \mathrm{~h}$. A small amount of the crystalline nanorods have been formed at 12.50 and $13.75 \mathrm{mM}$.

To further investigate when crystalline nanorods formed, we also synthesized two samples using precursor concentrations of 12.5 and $13.75 \mathrm{mM}$ at $250{ }^{\circ} \mathrm{C}$ for $2 \mathrm{~h}$. Total scattering data were collected (Figure S29), and the PDFs obtained from these two samples are shown in Figure 9. As evident in the small increase of intensity of the corner-sharing peak and the appearance of peaks at $\mathrm{r}=7.6 \AA$ and $\mathrm{r}=8.5 \AA$ in the PDFs, a small number of crystalline nanorods appear to have formed. This suggests that there is an optimal concentration for minimizing the formation of the amorphous nanoparticles at ca. $15 \mathrm{mM}$.

\section{Conclusion}

Through PDF analysis combined with SAXS and TEM, we have studied the structure of tungsten oxide nanomaterials synthesized by thermal decomposition of ammonium metatungstate in oleylamine. ${ }^{44}$ The size and shape of the nanoparticles can be controlled through precursor concentration, and it is possible to produce both spherical nanoparticles and nanorods. The spherical nanoparticles formed at the lowest precursor concentration (below $10 \mathrm{mM}$ ) are 
amorphous and their local structure is not similar to any previously reported known tungsten oxide. Instead, the structure is related to the polyoxometalate paratungstate B. The nanoparticles thus adopt an amorphous structure that is composed of a network of triads of edge-sharing [ $\left.\mathrm{WO}_{6}\right]-$ octahedra which are connected through corner-sharing $\left[\mathrm{WO}_{6}\right]$-octahedra. The size of the nanoparticles can be increased by increasing the precursor concentration. At $5 \mathrm{mM}$ precursor concentration, the average size of the amorphous particles is ca. $2 \mathrm{~nm}$, while it can be increased to $4 \mathrm{~nm}$ at $10 \mathrm{mM}$.

Increasing the precursor concentration to $15 \mathrm{mM}$ yields nanorods. These are nanocrystalline, however, their structures are not well-described by any known tungsten oxide. Instead, we used a $\mathrm{W}$-substituted $\mathrm{Nb}_{2} \mathrm{WO}_{8}$ crystal structure containing bipyramidal pentagonal columns to model the PDFs. At 20 and $25 \mathrm{mM}$ AMT, nanorods were also formed, but so were a secondary phase of smaller, amorphous nanoparticles. By raising the synthesis temperature from $250{ }^{\circ} \mathrm{C}$ to $300{ }^{\circ} \mathrm{C}$ all the amorphous nanoparticles converted into crystalline nanorods indicating that the nanorods grow from the smaller amorphous nanoparticles.

The study highlights the large effects nanosizing may have on the atomic structure of materials and to the best of our knowledge, this is the first observation of amorphous structure induced by the nanoparticle size. Neither the amorphous nanoparticles or crystalline nanorods synthesized and characterized here could be described using known tungsten oxide structures. This highlights the need for further insight into size-dependent structure, as understanding atomic structure is a prerequisite for further nanomaterial development.

\section{Experimental methods}




\section{Synthesis}

Tungsten oxide nanoparticles were prepared by heating a $20 \mathrm{~mL}$ solution of oleylamine (Merck/Sigma Aldrich, Technical grade $70 \%, 98 \%$ primary amines.) and ammonium metatungstate hydrate, $\left(\mathrm{NH}_{4}\right)_{6}\left[\mathrm{H}_{2} \mathrm{~W}_{12} \mathrm{O}_{40}\right] \times \mathrm{xH}_{2} \mathrm{O}$, (Merck/Sigma Aldrich, trace metal basis 99.99 $\%$ ) to $250{ }^{\circ} \mathrm{C}$ under nitrogen flow in a 3-necked round-bottomed flask for $2 \mathrm{~h}$. All chemicals were used as received. After $2 \mathrm{~h}$ of heating at $250{ }^{\circ} \mathrm{C}$, the solutions were left at room temperature to cool down. The samples for Small-Angle X-ray Scattering (SAXS) and Transmission Electron Microscopy measurements were taken directly from the reaction mixture and suspended in toluene. The remaining particles were then washed with ethanol and acetone, then centrifuged to obtain a brown (the 5 and $10 \mathrm{mM}$ samples) or blue powder (the 15,20 and $25 \mathrm{mM}$ ). Five samples were prepared with the AMT concentrations 5, 10,15,20, and $25 \mathrm{mM}$. The synthesis was also performed with $25 \mathrm{mM}$ precursor concentration for $3 \mathrm{~h}$ at 250 and $300{ }^{\circ} \mathrm{C}$.

\section{Total scattering and Pair Distribution Function analysis}

Total Scattering data were measured at the beamlines DanMAX at MAXIV, P02.158 at PETRA III, DESY and 11ID-B at APS, Argonne National Laboratory. The samples were loaded in 1.00 mm Kapton capillaries (inner diameter) and data were measured using the rapid acquisition PDF setup $^{59}$ with the wavelengths $0.3542 \AA$ (DanMAX), $0.2072 \AA$ (P02.1) and 0.2114 P (11ID-B). Integration of the $2 \mathrm{D}$ pattern into $1 \mathrm{D}$ patterns was done in Fit2D. ${ }^{60}$ Background subtraction, normalization and Fourier transformation into the PDFs were done in PDFgetX3. For the DESY and APS data, the Q-range from 0.5 to Q of $24 \AA^{-1}$ was included. ${ }^{61}$ while the $\mathrm{Q}_{\max }$ value for the DanMAX data was $19.5 \AA^{-1}$. The scattering pattern obtained from an empty Kapton capillary was 
used for background correction. Fitting using crystal structure models was done in PDFgui ${ }^{62}$ while fits including the models for amorphous structures were done using Diffpy-CMI. ${ }^{63}$

\section{Small-Angle X-ray Scattering}

The nanoparticles suspended in toluene (WMR, $99 \%$ ) were sonicated for $2 \mathrm{~h}$ and loaded in quartz capillaries with an inner diameter of $1.5 \mathrm{~mm}$. The small-angle scattering from the suspension was measured at room temperature using a SAXSLab instrument at the Niels Bohr Institute, University of Copenhagen, with an X-ray wavelength of $1.54 \AA$. SAXS data measured from toluene and an empty quartz capillary were used for background collection. The data were integrated using the program Saxsgui and analyzed with Diffpy-CMI, ${ }^{63}$ which uses SASVIEW functions. ${ }^{48}$ Further details of the modelling is available in the Supporting Information.

\section{Transmission Electron Microscopy}

TEM grids (Agar scientific, 200 mesh $\mathrm{Cu}$ ) were prepared by drop-casting suspensions of the nanoparticles in ethanol on the grids. Images were taken with an FEI Tecnai T20 G2 microscope and processed with FIJI. ${ }^{64}$

\section{Acknowledgements}

We are grateful to the Villum Foundation for financial support through a Villum Young Investigator grant (VKR00015416). We acknowledge the Carlsberg Foundation for financial support through grants CF14-0652 and CF17-0976. Funding from the Danish Ministry of Higher Education and Science through the SMART Lighthouse is gratefully acknowledged. We thank DANSCATT (supported by the Danish Agency for Science and Higher Education) for support. 
We acknowledge DESY (Hamburg, Germany), a member of the Helmholtz Association HGF, for the provision of experimental facilities. Parts of this research were carried out at P02.1 and we would like to thank Martin Etter for assistance in using the beamline. We acknowledge MAX IV Laboratory for time on Beamline DanMAX under Proposal 20200731. Research conducted at MAX IV is supported by the Swedish Research council under contract 2018-07152, the Swedish Governmental Agency for Innovation Systems under contract 2018-04969, and Formas under contract 2019-02496. DanMAX is funded by the NUFI grant no. 4059-00009B. This research used resources of the Advanced Photon Source, a U.S. Department of Energy (DOE) Office of Science User Facility, operated for the DOE Office of Science by Argonne National Laboratory under Contract No. DE-AC02-06CH11357. Part of this work was performed in part at DTU Danchip/Cen, the National Center for Micro-and Nanofabrication at the Technical University of Denmark. This work benefited from the use of the SasView application, originally developed under NSF award DMR-0520547. SasView contains code developed with funding from the European Union's Horizon 2020 research and innovation programme under the SINE2020 project, grant agreement No 654000 .

\section{REFERENCES}

1. Kim, B. H.; Hackett, M. J.; Park, J.; Hyeon, T., Synthesis, Characterization, and Application of Ultrasmall Nanoparticles. Chem. Mater. 2014, 26 (1), 59-71.

2. Christiansen, T. L.; Cooper, S. R.; Jensen, K. M. Ø., There's no place like real-space: elucidating size-dependent atomic structure of nanomaterials using pair distribution function analysis. Nanoscale Adv. 2020, 2 (6), 2234-2254.

3. Roduner, E., Size matters: why nanomaterials are different. Chem. Soc. Rev. 2006, 35 (7), 583-592.

4. Jin, R.; Zeng, C.; Zhou, M.; Chen, Y., Atomically Precise Colloidal Metal Nanoclusters and Nanoparticles: Fundamentals and Opportunities. Chem. Rev. 2016, 116 (18), 10346-10413.

5. Liu, L.; Corma, A., Metal Catalysts for Heterogeneous Catalysis: From Single Atoms to Nanoclusters and Nanoparticles. Chem. Rev. 2018, 118 (10), 4981-5079. 
6. Sáenz-Trevizo, A.; Hodge, A. M., Nanomaterials by design: a review of nanoscale metallic multilayers. Nanotechnology 2020, 31 (29), 292002.

7. Sun, S.; Zeng, H.; Robinson, D. B.; Raoux, S.; Rice, P. M.; Wang, S. X.; Li, G., Monodisperse $\mathrm{MFe}_{2} \mathrm{O}_{4}(\mathrm{M}=\mathrm{Fe}, \mathrm{Co}, \mathrm{Mn})$ Nanoparticles. J. Am. Chem. Soc. 2004, 126 (1), $273-$ 279.

8. Hens, Z.; De Roo, J., Atomically Precise Nanocrystals. J. Am. Chem. Soc. 2020, 142 (37), 15627-15637.

9. Burda, C.; Chen, X.; Narayanan, R.; El-Sayed, M. A., Chemistry and Properties of Nanocrystals of Different Shapes. Chem. Rev. 2005, 105 (4), 1025-1102.

10. Kovalenko, M. V.; Manna, L.; Cabot, A.; Hens, Z.; Talapin, D. V.; Kagan, C. R.; Klimov, V. I.; Rogach, A. L.; Reiss, P.; Milliron, D. J.; Guyot-Sionnnest, P.; Konstantatos, G.; Parak, W. J.; Hyeon, T.; Korgel, B. A.; Murray, C. B.; Heiss, W., Prospects of Nanoscience with Nanocrystals. ACS Nano 2015, 9 (2), 1012-1057.

11. Akkerman, Q. A.; Motti, S. G.; Srimath Kandada, A. R.; Mosconi, E.; D'Innocenzo, V.; Bertoni, G.; Marras, S.; Kamino, B. A.; Miranda, L.; De Angelis, F.; Petrozza, A.; Prato, M.; Manna, L., Solution Synthesis Approach to Colloidal Cesium Lead Halide Perovskite Nanoplatelets with Monolayer-Level Thickness Control. J. Am. Chem. Soc. 2016, 138 (3), 10101016.

12. Auffan, M.; Rose, J.; Bottero, J.-Y.; Lowry, G. V.; Jolivet, J.-P.; Wiesner, M. R., Towards a definition of inorganic nanoparticles from an environmental, health and safety perspective. Nat. Nanotechnol. 2009, 4 (10), 634-641.

13. Michel, F. M.; Ehm, L.; Antao, S. M.; Lee, P. L.; Chupas, P. J.; Liu, G.; Strongin, D. R.; Schoonen, M. A. A.; Phillips, B. L.; Parise, J. B., The Structure of Ferrihydrite, a Nanocrystalline Material. Science 2007, 316 (5832), 1726.

14. Funnell, N. P.; Fulford, M. F.; Inoué, S.; Kletetschka, K.; Michel, F. M.; Goodwin, A. L., Nanocomposite structure of two-line ferrihydrite powder from total scattering. Commun.Chem. 2020, 3 (1), 22.

15. Gilbert, B.; Huang, F.; Zhang, H.; Waychunas, G. A.; Banfield, J. F., Nanoparticles: Strained and Stiff. Science 2004, 305 (5684), 651.

16. Gary, D. C.; Flowers, S. E.; Kaminsky, W.; Petrone, A.; Li, X.; Cossairt, B. M., SingleCrystal and Electronic Structure of a $1.3 \mathrm{~nm}$ Indium Phosphide Nanocluster. J. Am. Chem. Soc. 2016, 138 (5), 1510-1513.

17. Zhang, Y. L.; Jin, X. J.; Rong, Y. H.; Hsu, T. Y.; Jiang, D. Y.; Shi, J. L., The size dependence of structural stability in nano-sized $\mathrm{ZrO}_{2}$ particles. Mater. Sci. Eng. A 2006, 438-440, 399-402.

18. Bumajdad, A.; Nazeer, A. A.; Al Sagheer, F.; Nahar, S.; Zaki, M. I., Controlled Synthesis of $\mathrm{ZrO}_{2}$ Nanoparticles with Tailored Size, Morphology and Crystal Phases via Organic/Inorganic Hybrid Films. Sci. Rep. 2018, 8 (1), 3695.

19. Christiansen, T. L.; Bøjesen, E. D.; Juelsholt, M.; Etheridge, J.; Jensen, K. M. Ø., Size Induced Structural Changes in Molybdenum Oxide Nanoparticles. ACS Nano 2019, 13 (8), 87258735 .

20. Jensen, K. M. Ø.; Juhas, P.; Tofanelli, M. A.; Heinecke, C. L.; Vaughan, G.; Ackerson, C. J.; Billinge, S. J. L., Polymorphism in magic-sized $\mathrm{Au}_{144}(\mathrm{SR})_{60}$ clusters. Nat. Commun. 2016, 7 , 11859. 
21. Yan, J.; Malola, S.; Hu, C.; Peng, J.; Dittrich, B.; Teo, B. K.; Häkkinen, H.; Zheng, L.; Zheng, N., Co-crystallization of atomically precise metal nanoparticles driven by magic atomic and electronic shells. Nat. Commun. 2018, 9 (1), 3357.

22. Heaven, M. W.; Dass, A.; White, P. S.; Holt, K. M.; Murray, R. W., Crystal Structure of the Gold Nanoparticle $\left[\mathrm{N}\left(\mathrm{C}_{8} \mathrm{H}_{17}\right)_{4}\right]\left[\mathrm{Au}_{25}\left(\mathrm{SCH}_{2} \mathrm{CH}_{2} \mathrm{Ph}\right)_{18}\right]$. J. Am. Chem. Soc. 2008, 130 (12), 37543755 .

23. Grewe, T.; Meggouh, M.; Tüysüz, H., Nanocatalysts for Solar Water Splitting and a Perspective on Hydrogen Economy. Chem. Asian J. 2016, 11 (1), $22-42$.

24. Santato, C.; Ulmann, M.; Augustynski, J., Photoelectrochemical Properties of Nanostructured Tungsten Trioxide Films. J. Phys. Chem. B 2001, 105 (5), 936-940.

25. Tian, Y.; Cong, S.; Su, W.; Chen, H.; Li, Q.; Geng, F.; Zhao, Z., Synergy of $\mathrm{W}_{18} \mathrm{O}_{49}$ and Polyaniline for Smart Supercapacitor Electrode Integrated with Energy Level Indicating Functionality. Nano Lett. 2014, 14 (4), 2150-2156.

26. Qiu, M.; Sun, P.; Shen, L.; Wang, K.; Song, S.; Yu, X.; Tan, S.; Zhao, C.; Mai, W., WO3 nanoflowers with excellent pseudo-capacitive performance and the capacitance contribution analysis. J. Mater. Chem. A 2016, 4 (19), 7266-7273.

27. Peng, H.; Liu, P.; Lin, D.; Deng, Y.; Lei, Y.; Chen, W.; Chen, Y.; Lin, X.; Xia, X.; Liu, A., Fabrication and multifunctional properties of ultrasmall water-soluble tungsten oxide quantum dots. Chem. Commun. 2016, 52 (61), 9534-9537.

28. Morales, W.; Cason, M.; Aina, O.; de Tacconi, N. R.; Rajeshwar, K., Combustion Synthesis and Characterization of Nanocrystalline $\mathrm{WO}_{3}$. J. Am. Chem. Soc. 2008, 130 (20), 63186319.

29. Wang, S.; Kershaw, S. V.; Li, G.; Leung, M. K. H., The self-assembly synthesis of tungsten oxide quantum dots with enhanced optical properties. J. Mater. Chem. C 2015, 3 (14), 3280-3285.

30. Huang, X.-J.; Bao, J.; Han, Y.; Cui, C.-W.; Wang, J.-X.; Zeng, X.-F.; Chen, J.-F., Controllable synthesis and evolution mechanism of tungsten bronze nanocrystals with excellent optical performance for energy-saving glass. J. Mater. Chem. C 2018, 6 (29), 7783-7789.

31. Bai, S.; Zhang, K.; Shu, X.; Chen, S.; Luo, R.; Li, D.; Chen, A., Carboxyl-directed hydrothermal synthesis of WO3 nanostructures and their morphology-dependent gas-sensing properties. CrystEngComm 2014, 16 (44), 10210-10217.

32. Bai, S.; Zhang, K.; Luo, R.; Li, D.; Chen, A.; Liu, C. C., Low-temperature hydrothermal synthesis of WO3 nanorods and their sensing properties for $\mathrm{NO}_{2}$. J. Mater. Chem. 2012, 22 (25), 12643-12650.

33. Zhang, H.; Yao, M.; Bai, L.; Xiang, W.; Jin, H.; Li, J.; Yuan, F., Synthesis of uniform octahedral tungsten trioxide by RF induction thermal plasma and its application in gas sensing. CrystEngComm 2013, 15 (7), 1432-1438.

34. Zahoor, M. T.; Ahmad, M.; Maaz, K.; Karim, S.; Waheed, K.; Ali, G.; Hussain, S.; Hussain, S. Z.; Nisar, A., Tungsten oxide multifunctional nanostructures: Enhanced environmental and sensing applications. Mater. Chem. Phys. 2019, 221, 250-257.

35. Sundberg, M.; Werner, P.E.; Zibrov, I. P., X-ray powder crystal structure analysis of high pressure tungsten dioxide On the information in weak reflections. Z. Kristallogr. 1994, 209 (8), 662-666.

36. Palmer, D. J.; Dickens, P. G., Tungsten dioxide: structure refinement by powder neutron diffraction. Acta Crystallogr. B 1979, 35 (9), 2199-2201. 
37. Tilley, R. J. D., The Crystal Chemistry of the Higher Tungsten Oxides. In The Chemistry of Non-Sag Tungsten, Pergamon: Oxford, 1995; pp 93-109.

38. Zheng, H.; Ou, J. Z.; Strano, M. S.; Kaner, R. B.; Mitchell, A.; Kalantar-zadeh, K., Nanostructured Tungsten Oxide - Properties, Synthesis, and Applications. Adv. Funct. Mater. 2011, 21 (12), 2175-2196.

39. Gerand, B.; Nowogrocki, G.; Guenot, J.; Figlarz, M., Structural study of a new hexagonal form of tungsten trioxide. J. Solid State Chem. 1979, 29 (3), 429-434.

40. Oi, J.; Kishimoto, A.; Kudo, T.; Hiratani, M., Hexagonal tungsten trioxide obtained from peroxo-polytungstate and reversible lithium electro-intercalation into its framework. J. Solid State Chem. 1992, 96 (1), 13-19.

41. N. N. Greenwood, A. E., Chemistry of the elements. 2nd ed.; Butterworth Heinemann: 2013.

42. Lugovskaya, L. A.; Aleshina, L. A.; Kalibaeva, G. M.; Fofanov, A. D., X-ray study and structure simulation of amorphous tungsten oxide. Acta Crystallogr. B 2002, 58 (4), 576-586.

43. Jürgen, A.; Joachim, M.; Peter, L.; Siegfried, S., Evaluation of the Structure of Amorphous Tungsten Oxide $\mathrm{W}_{28} \mathrm{O}_{72}$ by the Combination of Electron-, X-Ray- and NeutronDiffraction (Three-Beam Experiment). Z. Naturforsch. A 2006, 61 (3-4), 189-196.

44. Soultanidis, N.; Zhou, W.; Kiely, C. J.; Wong, M. S., Solvothermal Synthesis of Ultrasmall Tungsten Oxide Nanoparticles. Langmuir 2012, 28 (51), 17771-17777.

45. Kotlarchyk, M.; Chen, S. H., Analysis of small angle neutron scattering spectra from polydisperse interacting colloids. J. Chem. Phys. 1983, 79 (5), 2461-2469.

46. Li, T.; Senesi, A. J.; Lee, B., Small Angle X-ray Scattering for Nanoparticle Research. Chem. Rev. 2016, 116 (18), 11128-11180.

47. Larsen, A. H.; Pedersen, J. S.; Arleth, L., Assessment of structure factors for analysis of small-angle scattering data from desired or undesired aggregates. J. Appl. Crystallogr. 2020, 53 (4), 991-1005.

48. $\quad$ https://www.sasview.org/.

49. Juelsholt, M.; Lindahl Christiansen, T.; Jensen, K. M. Ø., Mechanisms for Tungsten Oxide Nanoparticle Formation in Solvothermal Synthesis: From Polyoxometalates to Crystalline Materials. J. Phys. Chem. C 2019, 123 (8), 5110-5119.

50. Lou, X. W.; Zeng, H. C., An Inorganic Route for Controlled Synthesis of W18O49 Nanorods and Nanofibers in Solution. Inorg. Chem. 2003, 42 (20), 6169-6171.

51. Lee, K.; Seo, W. S.; Park, J. T., Synthesis and Optical Properties of Colloidal Tungsten Oxide Nanorods. J. Am. Chem. Soc. 2003, 125 (12), 3408-3409.

52. Gu, G.; Zheng, B.; Han, W. Q.; Roth, S.; Liu, J., Tungsten Oxide Nanowires on Tungsten Substrates. Nano Lett. 2002, 2 (8), 849-851.

53. Luo, J. Y.; Chen, F.; Cao, Z.; Zheng, W. H.; Liu, H. C.; Li, Y. D.; Yang, G. T.; Zeng, Q. G., Complex three-dimensional tungsten oxide nanowire networks: controllable synthesis and growth mechanism. CrystEngComm 2015, 17 (4), 889-894.

54. $\quad$ Dören, R.; Leibauer, B.; Lange, M. A.; Schechtel, E.; Prädel, L.; Panthöfer, M.; Mondeshki, M.; Tremel, W., Gram-scale selective synthesis of $\mathrm{WO}_{3-\mathrm{x}}$ nanorods and (NH4)xWO3 ammonium tungsten bronzes with tunable plasmonic properties. Nanoscale 2021, 13 (17), 81468162.

55. Monica, L., The Crystal Structure of Nb2WO8. Acta Chem. Scand. 1972, 26, 2932 - 2940. 
56. Sundberg, M.; Zakharov, N. D.; Zibrov, I. P.; Barabanenkov, Y. A.; Filonenko, V. P.; Werner, $\mathrm{P}$., Two high-pressure tungsten oxide structures of $\mathrm{W}_{3} \mathrm{O}_{8}$ stoichiometry deduced from high-resolution electron microscopy images. Acta Crystallogr. B 1993, 49 (6), 951-958.

57. Stephenson, N., A structural investigation of some stable phases in the region $\mathrm{Nb}_{2} \mathrm{O}_{5} \cdot \mathrm{WO}_{3^{-}}$ $\mathrm{WO}_{3}$. Acta Crystallogr. B 1968, 24 (5), 637-653.

58. Dippel, A.-C.; Liermann, H.-P.; Delitz, J. T.; Walter, P.; Schulte-Schrepping, H.; Seeck, O. H.; Franz, H., Beamline P02.1 at PETRA III for high-resolution and high-energy powder diffraction. J. Syncrotron Radiat. 2015, 22 (3), 675-687.

59. Chupas, P. J.; Qiu, X.; Hanson, J. C.; Lee, P. L.; Grey, C. P.; Billinge, S. J. L., Rapidacquisition pair distribution function (RA-PDF) analysis. J. Appl. Crystallogr. 2003, 36 (6), 13421347.

60. Hammersley, A., FIT2D: a multi-purpose data reduction, analysis and visualization program. J. Appl. Crystallogr. 2016, 49 (2), 646-652.

61. Juhas, P.; Davis, T.; Farrow, C. L.; Billinge, S. J. L., PDFgetX3: a rapid and highly automatable program for processing powder diffraction data into total scattering pair distribution functions. J. Appl. Crystallogr. 2013, 46 (2), 560-566.

62. Farrow, C.L.; Juhas, P.; Liu, J. W.; Bryndin, D.; Božin, E. S.; Bloch, J.; Th, P.; Billinge, S. J. L., PDFfit2 and PDFgui: computer programs for studying nanostructure in crystals. J. Phys.: Condens. Matter 2007, 19 (33), 335219.

63. Juhas, P.; Farrow, C. L.; Yang, X.; Knox, K. R.; Billinge, S. J. L., Complex modeling: a strategy and software program for combining multiple information sources to solve ill posed structure and nanostructure inverse problems. Acta Cryst. A 2015, 71 (6), 562-568.

64. Schindelin, J.; Arganda-Carreras, I.; Frise, E.; Kaynig, V.; Longair, M.; Pietzsch, T.; Preibisch, S.; Rueden, C.; Saalfeld, S.; Schmid, B.; Tinevez, J.-Y.; White, D. J.; Hartenstein, V.; Eliceiri, K.; Tomancak, P.; Cardona, A., Fiji: an open-source platform for biological-image analysis. Nat. Methods. 2012, 9 (7), 676-682. 